\title{
СТРУКТУРЫ ГРАНИТОВ САЛМИНСКОГО ПЛУТОНА, КАРЕЛИЯ
}

Войтеховский Ю.Л. ${ }^{1}{ }^{2}$, Петров Д.А. ${ }^{1}$, Захарова А.А. ${ }^{1}$

${ }^{1}$ Санкт-Петербургский Горный университет, Санкт-Петербург, voytekhovskiy_yul@pers.spmi.ru

${ }^{2}$ Геологический институт ФИЦ КНЦ РАН, Апатиты, woyt@geoksc.apatity.ru

В предыдущей статье авторов [3] показано, как математический метод, изложенный в работах [4-6], позволяет однозначно идентифицировать структуру горной породы, в первую очередь для расчленения и картирования гранитоидных интрузий [7]. Рассмотренный пример - граниты массива Акжайляу [1] - может показаться слишком простым, поскольку физиография горной породы сведена к соотношению зёрен кварца и полевых шпатов. Далее рассмотрен пример, более приближённый к действительности - граниты Салминского плутона, Карелия [2], в которых различены пять минеральных фаз (рис. 1, 2): кварц (жёлтый), плагиоклаз (голубой), K-Na полевой шпат (красный), биотит (грязно-зелёный) и акцессории (фиолетовый). Для определённости поставим вопрос, различаются ли петрографические структуры в двух данных шлифах?

В обоих случаях матрицы $\left[P_{i j}\right]$ вероятностей межзерновых контактов приводятся к диагональному виду, отвечающему структуре $S_{5}^{2}$. Структурная индикатриса - трёхполостный гиперболоид в пространстве $\left(m_{1}, m_{2}, \ldots m_{5}\right)$. Индексы соответствуют строкам и столбцам матриц и означают: 1 - кварц, 2 - плагиоклаз, 3 - K-Na полевой шпат, 4 - биотит, 5 - акцессории. Таким образом, оба образца относятся к одному структурному типу, хотя их органи-

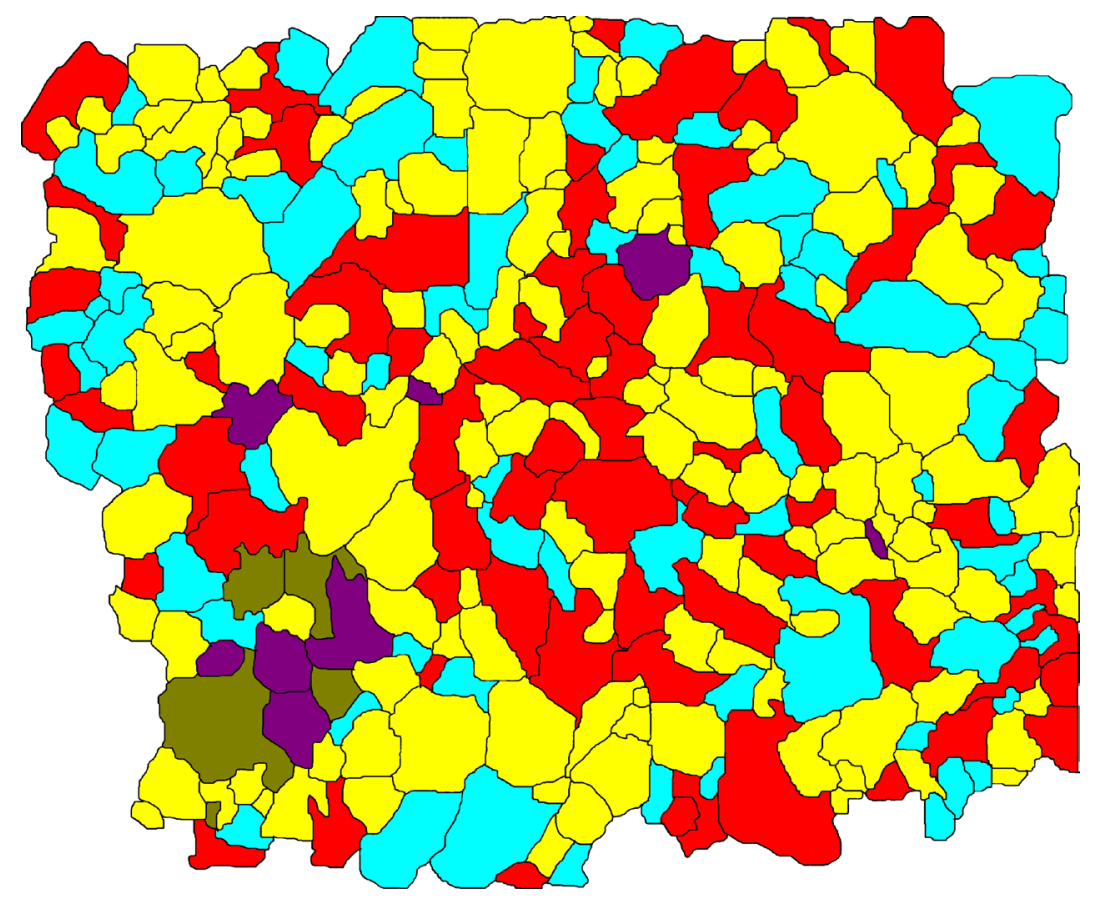

Рис. 1. Петрографический шлиф №1. Среднезернистый питерлит, основная масса без порфировых вкрапленников. Раскраска условная, пояснения в тексте. Размер по вертикали 1 см. 


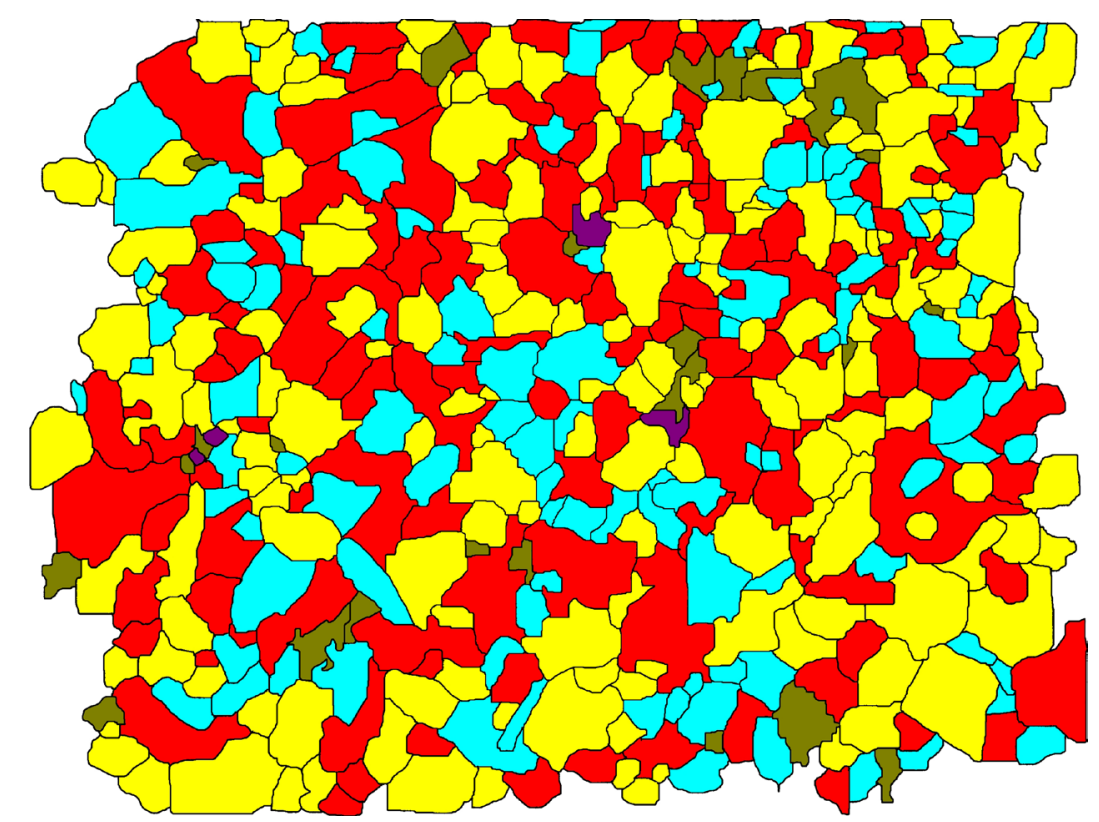

Рис. 2. Петрографический шлиф №2. Порфировидный микроклин-альбитовый гранит, основная масса без вкрапленников. Размер по вертикали 1 см.

зация, фиксируемая всей совокупностью вероятностей $p_{i j}$ межзерновых контактов, несколько различна.

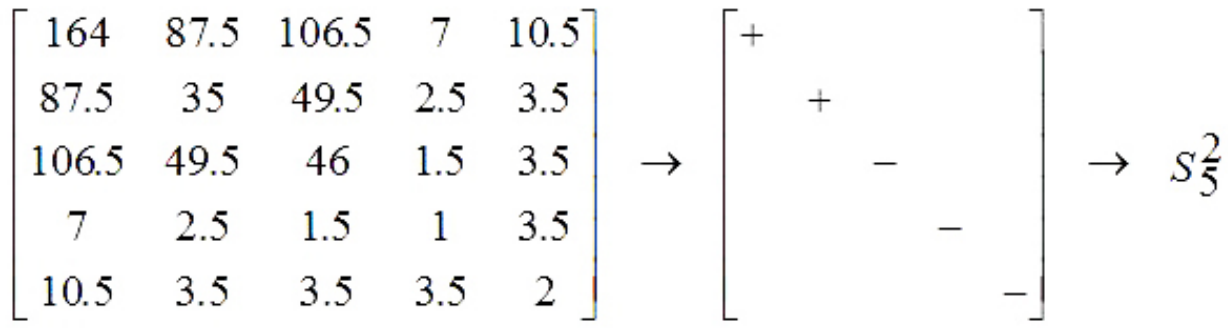

$$
\begin{aligned}
& {\left[\begin{array}{ccccc}
148 & 98 & 182 & 21.5 & 4.5 \\
98 & 53 & 102.5 & 15 & 2 \\
182 & 102.5 & 105 & 17.5 & 2.5 \\
21.5 & 15 & 17.5 & 5 & 2.5 \\
4.5 & 2 & 2.5 & 2.5 & 0
\end{array}\right] \rightarrow\left[\begin{array}{lll}
+ & & \\
+ & \\
& - \\
& & - \\
& &
\end{array}\right] \rightarrow S_{5}^{2}}
\end{aligned}
$$

Анализ шлифов может быть продолжен, поскольку акцессории и биотит составляют в граните весьма малую долю. Применим метод вычитания акцессориев [6], поочерёдно удаляя их из рассмотрения, т.е. убирая соответствующие строки и столбцы из матриц $\left[P_{i j}\right]$. Без акцессориев в обоих случаях получаем тип структуры $S_{4}^{2}$. Индикатриса - двуполостный гиперболоид в пространстве $\left(m_{1}, m_{4}, m_{3}, m_{4}\right)$.

$$
\left[\begin{array}{cccc}
164 & 87.5 & 106.5 & 7 \\
87.5 & 35 & 49.5 & 2.5 \\
106.5 & 49.5 & 46 & 1.5 \\
7 & 2.5 & 1.5 & 1
\end{array}\right] \rightarrow\left[\begin{array}{lll}
+ & & \\
& + & \\
& - \\
& & -
\end{array}\right] \rightarrow S_{4}^{2}
$$




$$
\left[\begin{array}{cccc}
148 & 98 & 182 & 21.5 \\
98 & 53 & 102.5 & 15 \\
182 & 102.5 & 105 & 17.5 \\
21.5 & 15 & 17.5 & 5
\end{array}\right] \rightarrow\left[\begin{array}{lll}
+ & & \\
+ & \\
& - \\
& & -
\end{array}\right] \rightarrow S_{4}^{2}
$$

Без биотита получаем структуры $S_{4}{ }^{1}$ и $S_{4}{ }^{2}$. Индикатрисы - трёхполостный и двуполостный гиперболоиды в пространстве $\left(m_{1}, m_{4}, m_{3}, m_{4}\right)$. Вместе с предыдущим результатом это означает, что в петрографическом шлифе №1 акцессории и биотит образуют статистически эквивалентные срастания, а в шлифе №2 - разные.

$$
\begin{aligned}
& {\left[\begin{array}{cccc}
164 & 87.5 & 106.5 & 10.5 \\
87.5 & 35 & 49.5 & 3.5 \\
106.5 & 49.5 & 46 & 3.5 \\
10.5 & 3.5 & 3.5 & 2
\end{array}\right] \rightarrow\left[\begin{array}{lll}
+ & & \\
& + & \\
& & - \\
& & -
\end{array}\right] \rightarrow S_{4}^{2}} \\
& {\left[\begin{array}{cccc}
148 & 98 & 182 & 4.5 \\
98 & 53 & 102.5 & 2 \\
182 & 102.5 & 105 & 2.5 \\
4.5 & 2 & 2.5 & 0
\end{array}\right] \rightarrow\left[\begin{array}{ll}
+ & \\
- &
\end{array}\right] \rightarrow S_{4}^{1}}
\end{aligned}
$$

Без акцессориев и биотита основная (каркасообразующая) часть изучаемых гранитов имеет структуру $S_{3}{ }^{1}$. Индикатриса - двуполостный гиперболоид в пространстве $\left(m_{1}, m_{2}, m_{3}\right)$.

$$
\begin{aligned}
& {\left[\begin{array}{ccc}
164 & 87.5 & 106.5 \\
87.5 & 35 & 49.5 \\
106.5 & 49.5 & 46
\end{array}\right] \rightarrow\left[\begin{array}{lll}
+ & & \\
& - & \\
& & -
\end{array}\right] \rightarrow S_{3}^{1}} \\
& {\left[\begin{array}{ccc}
148 & 98 & 182 \\
98 & 53 & 102.5 \\
182 & 102.5 & 105
\end{array}\right] \rightarrow\left[\begin{array}{lll}
+ & & \\
& - & \\
& & -
\end{array}\right] \rightarrow S_{3}^{1}}
\end{aligned}
$$

Таким образом, предложенный ранее математический метод типизации петрографических структур по статистикам межзерновых срастаний позволяет выявлять даже тонкие особенности организации горных пород. Это позволяет применять его для расчленения и картирования гранитоидных интрузий. Рутинные алгебраические операции с как угодно большими матрицами компьютеризованны [8]. 


\section{Список литературы}

1. Бескин С.М., Ларин В.Н., Марин Ю.Б. Редкометалльные гранитовые формации. Л.: Недра. 1979. 280 с.

2. Бескин С.М., Лишневский Э.Н., Диденко М.И. Строение Питкярантского гранитного массива в Северном Приладожье, Карелия / // Изв. АН СССР. Сер. геол. 1983. № 3. С. 19-26.

3. Войтеховский Ю.Л., Захарова А.А. Структура гранита массива Акжайляу, Казахстан // Наст. сборник.

4. Войтеховский Ю.Л. К проблеме организации горных пород // Изв. ВУЗов. Геол. и разведка. 1991. № 10. С. 34-39.

5. Войтеховский Ю.Л. Приложение теории квадратичных форм к проблеме классификации структур полиминеральных горных пород // Изв. ВУЗов. Геол. и разведка. 1995. № 1. С. 32-42.

6. Войтеховский Ю.Л. Количественный анализ петрографических структур: метод структурной индикатрисы и метод вычитания акцессориев // Изв. вузов. Геол. и разведка. 2000. № 1. С. 50-54.

7. Добрецов Г.Л., Марин Ю.Б., Бескин С.М., Лесков С.А. Принципы расчленения и картирования гранитоидных интрузий и выделения петрологометаллогенических вариантов гранитидных серий. СПб.: Изд-во ВСЕГЕИ. $2007.80 \mathrm{c}$.

8. http://www.wolframalpha.com/examples/mathematics/linear-algebra/ 